\title{
Controlled pore collapse to increase solute rejection of modified PES membranes
}

Zverina, Libor; Koch, Marcus; Andersen, Mads F.; Pinelo, Manuel; Woodley, John M.; Daugaard, Anders E.

Published in:

Journal of Membrane Science

Link to article, DOI:

10.1016/j.memsci.2019.117515

Publication date:

2020

Document Version

Peer reviewed version

Link back to DTU Orbit

Citation (APA):

Zverina, L., Koch, M., Andersen, M. F., Pinelo, M., Woodley, J. M., \& Daugaard, A. E. (2020). Controlled pore collapse to increase solute rejection of modified PES membranes. Journal of Membrane Science, 595, [117515]. https://doi.org/10.1016/j.memsci.2019.117515

\section{General rights}

Copyright and moral rights for the publications made accessible in the public portal are retained by the authors and/or other copyright owners and it is a condition of accessing publications that users recognise and abide by the legal requirements associated with these rights.

- Users may download and print one copy of any publication from the public portal for the purpose of private study or research.

- You may not further distribute the material or use it for any profit-making activity or commercial gain

- You may freely distribute the URL identifying the publication in the public portal 


\section{Journal Pre-proof}

Controlled pore collapse to increase solute rejection of modified PES membranes

Libor Zverina, Marcus Koch, Mads F. Andersen, Manuel Pinelo, John M. Woodley, Anders E. Daugaard

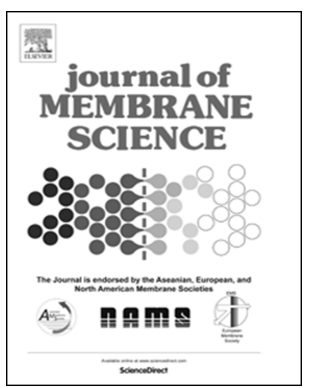

PII:

S0376-7388(19)31735-1

DOI:

https://doi.org/10.1016/j.memsci.2019.117515

Reference: MEMSCI 117515

To appear in: Journal of Membrane Science

Received Date: 4 June 2019

Revised Date: 23 September 2019

Accepted Date: 26 September 2019

Please cite this article as: L. Zverina, M. Koch, M.F. Andersen, M. Pinelo, J.M. Woodley, A.E. Daugaard, Controlled pore collapse to increase solute rejection of modified PES membranes, Journal of Membrane Science (2019), doi: https://doi.org/10.1016/j.memsci.2019.117515.

This is a PDF file of an article that has undergone enhancements after acceptance, such as the addition of a cover page and metadata, and formatting for readability, but it is not yet the definitive version of record. This version will undergo additional copyediting, typesetting and review before it is published in its final form, but we are providing this version to give early visibility of the article. Please note that, during the production process, errors may be discovered which could affect the content, and all legal disclaimers that apply to the journal pertain.

(C) 2019 Published by Elsevier B.V. 


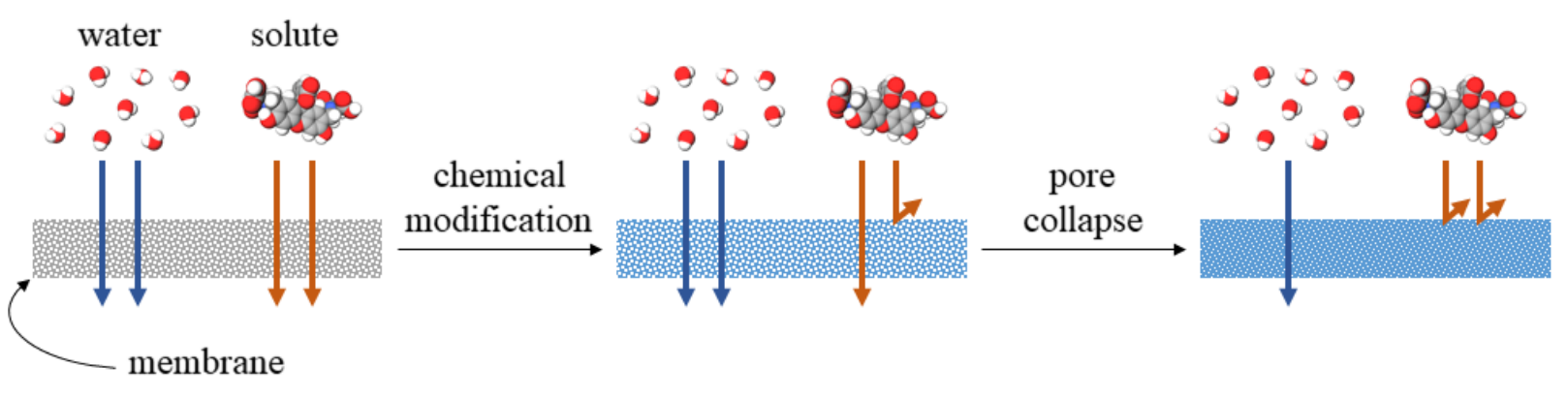




\section{Controlled pore collapse to increase solute rejection of modified PES}

\section{membranes}

Libor Zverina a, Marcus Koch b, Mads F. Andersen c, Manuel Pinelo a, John M.

Woodley a and Anders E. Daugaard a,*

a Department of Chemical and Biochemical Engineering, Technical University of Denmark, Søltofts Plads 229, 2800 Kgs. Lyngby, Denmark

b INM - Leibniz Institute for New Materials, Saarbrücken, Germany

c Aquaporin A/S, Nymøllevej 78, 2800 Kgs. Lyngby, Denmark

* Corresponding author. Email address: adt@kt.dtu.dk (A. E. Daugaard)

Keywords: commercial hollow-fiber polyethersulfone membrane, surface functionalization, heterogeneous reaction, solute rejection, controlled pore collapse, SI-ATRP

\section{ABSTRACT}

Pore collapse upon drying is a well-known phenomenon in ultrafiltration PES membranes. Here we demonstrate how alteration of membrane surface chemistry can be used to control the extent of pore collapse and ultimately to tailor membrane properties. Commercial hollow-fiber PES membranes were modified via surface-initiated ATRP to obtain different polymer-grafted membranes and were subsequently dried to facilitate pore collapse. The different polymer grafts could be used for controlling the water flux and solute rejection characteristics of the membranes. Controlled membrane pore collapse could be exploited to obtain higher rejection of sodium chloride, magnesium sulfate and calcein. Calcein as the largest solute showed almost full rejection $(98.9 \pm 0.3 \%)$ on the membrane. The chemical nature of the grafted polymer was directly reflected in the water flux-to-rejection ratio and the extent of pore collapse. 


\section{Introduction}

Polysulfone and polyethersulfone (PES) membranes, particularly in the form of hollow fibers, have been widely used in industrial applications due to their ease of production as well as thermal, chemical and mechanical endurance. PES membranes usually find applications in ultrafiltration $[1,2]$. However, by modification of the membranes, their solute rejection can be increased and their application can be extended to nanofiltration $[3,4]$ or reverse osmosis $[5,6]$. Here the PES membrane provides mechanical integrity and the active layer of the membrane is formed by surface modification.

Over time, several approaches for modification of membrane surfaces have been used [7]. Due to the relative inertness of polysulfone membranes, surface modification of membranes often go through a multistep methodology such as an initial chloromethylation, sulfonation, aminomethylation or carboxylation [8-10]. For thicker layers of polymers, popular methods have been radical crosslinking on the surface or direct radical graft copolymerization [11-13]. With establishment of surface initiated atom transfer radical polymerization (SI-ATRP) as a highly efficient method for surface modification [14-18], new possibilities to control the thickness and a broader choice of surface grafted polymers arose. This was demonstrated on membranes by Bruening [19] and Husson [20], who used SI-ATRP for surface modification of membranes. Using this versatile technique, the surface chemistry of PES membranes can be altered in a controlled manner by introducing various polymers with a wide selection of functional groups [21-27]. To allow SI-ATRP to take place from the PES surface, the membrane must first be activated by introduction of an ATRP initiator. This is commonly done by homogeneous chloromethylation $[8,28]$ or homogeneous lithiation $[29,30]$, which give accurate control over the degree of substitution, but cannot be applied to commercial and already-casted membranes, since these methods require dissolution of the polymer prior to the reaction. A few heterogeneous methods of 
introducing the initiator that do not require dissolution of the membrane have been published [31,9,32-35]. To our knowledge, the only example of heterogeneous activation of hollow-fiber PES membrane was reported by Higuchi et al. [31,9,32], who exploited FriedelCrafts acylation for modification of the surface of the hollow fibers. This leads to an easy control of the degree of substitution through reaction time. However, severe cross-linking of the membrane was observed, causing a significant drop in water flux of the activated membrane. As an alternative, heterogeneous ortholithiation has been reported for flat-sheet PES membranes by Guiver et al. [33,34], which we recently extended to include acylation using a range of acyl chlorides on commercially available polypropylene-supported flatsheet membranes [35]. These activation methods all open up for post-modification of membranes by SI-ATRP, which ultimately leads to membranes having a very wide selection of surface chemistries.

Another process that has high impact on performance of PES membranes is pore stability or pore collapse [36]. Pore collapse in PES membranes is a well-known phenomenon resulting in drastic reduction in water flux and loss of the porous microstructure upon drying. However, no studies have been found on how pore collapse affects the rejection characteristics of membranes. Therefore, we here aim here at exploiting a combination of surface modification and intentional pore collapse, targeting commercial hollow-fiber PES membranes with higher solute rejection and high water flux.

\section{Experimental}

\subsection{Materials}

Hollow-fiber polyethersulfone membranes (PES, Memsino PSH1-1060-B, MWCO 100$150 \mathrm{kDa}$, flux 50-200 L m² $\mathrm{h}^{-1}, 40 \mathrm{~cm}$ long fibers, inner diameter $0.8 \mathrm{~mm}$, treated with glycerol) were kindly donated by Aquaporin A/S. $n$-Butyllithium (n-BuLi, $2.5 \mathrm{M}$ in 
hexanes), copper(I) chloride (CuCl, purified, > 99 \%), 2,2'-bipyridyl (bipy, ReagentPlus ${ }^{\circledR}$, > $99 \%$ ), 2-hydroxyethyl methacrylate (HEMA, $97 \%$ ), 4-styrenesulfonic acid sodium salt hydrate (NaSS) and 1-bromobutane (BuBr, ReagentPlus ${ }^{\circledR}, 99$ \%) were purchased from Sigma-Aldrich (Merck). 4-(chloromethyl)benzoyl chloride (CMBC, > 98.0 \%) and 1vinylimidazole (VI, > 98 \%) were purchased from TCI chemicals. HEMA and VI were passed through a short plug flow column containing aluminum oxide (Sigma-Aldrich, activated, basic, Brockmann I) prior to using for SI-ATRP. All other chemicals were acquired from Sigma-Aldrich and were used as received.

\subsection{Characterization}

Fourier-transform infrared spectroscopy was carried out using Nicolet iS50 FT-IR spectrometer fitted with a diamond crystal attenuated total reflection accessory, which operated at a resolution of $4 \mathrm{~cm}^{-1}$ and 32 scans per measurement. The membrane samples were washed with ethanol and dried in air before analysis. The raw membrane spectra were normalized to the aromatic $\mathrm{C}=\mathrm{C}$ stretch at $1485 \mathrm{~cm}^{-1}$.

X-ray photoelectron spectroscopy (XPS) was conducted on a Thermo Scientific K-Alpha spectrometer. Membrane samples were washed with ethanol and placed in a vacuum oven at $50{ }^{\circ} \mathrm{C}$ for 5 days before the analysis. Monochromatized aluminum Ka radiation beam with diameter of $400 \mu \mathrm{m}$ was used to acquire survey spectra (pass energy $200 \mathrm{eV}$ ). Charge compensation was achieved using a flood gun. The Thermo Scientific Avantage software was used for digital acquisition and data processing.

Scanning electron microscopy (SEM) was performed on FEI Quanta $400 \mathrm{FEG}$ at $3{ }^{\circ} \mathrm{C}$. Membrane samples were washed with ethanol and dried in air. Secondary electron images were acquired in low vacuum mode (water vapor pressure $100 \mathrm{~Pa}$ ) at $10 \mathrm{kV}$ accelerating voltage. Wet (deionized water) membrane samples were placed on a cooling stage with 
water vapor pressure starting at $800 \mathrm{~Pa}$, which was gradually reduced ending at $200 \mathrm{~Pa}$. The images were taken when all water was evaporated.

\subsection{General procedure for synthesis of activated PES-Cl membranes - low-density regime}

PES membranes (20 fibers, each $40 \mathrm{~cm}$ long) were first submerged in ethanol for $2 \mathrm{~h}$ and then in diethyl ether for $0.5 \mathrm{~h}$. Afterwards, a pre-dried round-bottom flask was charged with a pre-dried magnetic stirrer and the previously-washed membranes. The reaction flask was sealed, evacuated and filled with $\mathrm{N}_{2}$ three times. Diethyl ether $\left(90 \mathrm{~mL}\right.$, bubbled with $\mathrm{N}_{2}$ for $20 \mathrm{~min})$ was added under $\mathrm{N}_{2}$ atmosphere and $n$-BuLi $(0.9 \mathrm{~mL}, 2.25 \mathrm{mmol})$ was added dropwise under $\mathrm{N}_{2}$ atmosphere at room temperature while stirring. The reaction mixture was stirred for $2 \mathrm{~h}$, thereafter the reaction was cooled to $0^{\circ} \mathrm{C}$ and a solution of $\mathrm{CMBC}$ (516.6 mg, $2.73 \mathrm{mmol}$, dissolved in $5 \mathrm{~mL}$ diethyl ether) was added slowly. After continued stirring for another $1 \mathrm{~h}$, the reaction was quenched by addition of ethanol $(25 \mathrm{~mL})$. The activated PES-Cl membranes were removed from the reaction flask, immersed into ethanol and placed on a shaking table for $1 \mathrm{~h}$. The membranes were stored in water at $5^{\circ} \mathrm{C}$ until further use.

FT-IR spectrum $\left(\mathrm{cm}^{-1}\right): 3096(\mathrm{C}-\mathrm{H}), 3069(\mathrm{C}-\mathrm{H}), 1668\left(\mathrm{R}_{2} \mathrm{~N}-\mathrm{C}=\mathrm{O}\right), 1577\left(\mathrm{C}=\mathrm{C}_{\text {arom }}\right), 1485$ $\left(\mathrm{C}=\mathrm{C}_{\text {arom}}\right), 1297(\mathrm{~S}=\mathrm{O}), 1237(\mathrm{C}-\mathrm{O}), 1148(\mathrm{~S}=\mathrm{O}), 1072(\mathrm{C}-\mathrm{O})$.

\subsection{Synthesis of high-density activated PES-Cl membranes}

High-density activated PES-Cl membranes were synthesized in accordance with the general procedure in which PES membranes (3 fibers, each $2.5 \mathrm{~cm}$ long), diethyl ether (50 mL), n-BuLi (2 mL, $5.00 \mathrm{mmol})$ and CMBC (1177.3 mg, $2.73 \mathrm{mmol})$ were used.

FT-IR spectrum (cm-1): $3096(\mathrm{C}-\mathrm{H}), 3069(\mathrm{C}-\mathrm{H}), 1722(\mathrm{C}=\mathrm{O}), 1675(\mathrm{C}=\mathrm{O}), 1577\left(\mathrm{C}=\mathrm{C}_{\text {arom}}\right)$, 1485 (C=Carom), 1297 (S=O), 1237 (C-O), 1148 (S=O), 1072 (C-O). 
2.5 General procedure for synthesis of grafted membranes via SI-ATRP from PES-Cl membranegrafted mPHEMA membranes

A round-bottom flask charged with $\mathrm{CuCl}(850.3 \mathrm{mg}, 8.59 \mathrm{mmol})$ and bipy $(2779.3 \mathrm{mg}$, $17.80 \mathrm{mmol})$ was evacuated and filled with $\mathrm{N}_{2}$ three times. HEMA $(70 \mathrm{~mL}, 577 \mathrm{mmol})$ and water:ethanol mixture $\left(70 \mathrm{~mL}, 1: 1, \mathrm{v} / \mathrm{v}\right.$, bubbled with $\mathrm{N}_{2}$ for $\left.1 \mathrm{~h}\right)$ were added. The mixture was purged with $\mathrm{N}_{2}$ for $1 \mathrm{~h}$. A second round-bottom flask equipped with a stirrer and 3 lowdensity activated PES-Cl membranes was evacuated and filled with $\mathrm{N}_{2}$ three times. The purged mixture $(40 \mathrm{~mL})$ was transferred under $\mathrm{N}_{2}$ into the round-bottom flask containing the membranes and kept under an inert atmosphere. Polymerization took place under stirring for 5,15 and $30 \mathrm{~min}$, respectively at $35^{\circ} \mathrm{C}$. The grafted membranes were removed from the polymerization bath, washed with water and ethanol, and then stored in water at $5^{\circ} \mathrm{C}$ until further use.

FT-IR spectrum (cm-1): 3096 (C-H), 3069 (C-H), 1726 (C=O), 1577 (C=Carom), 1485 $\left(\mathrm{C}=\mathrm{C}_{\text {arom}}\right), 1297(\mathrm{~S}=\mathrm{O}), 1237(\mathrm{C}-\mathrm{O}), 1148(\mathrm{~S}=\mathrm{O}), 1072(\mathrm{C}-\mathrm{O})$.

\subsection{Synthesis of grafted mPSS membranes via SI-ATRP from PES-Cl membrane}

Grafted mPSS membranes were synthesized in accordance with the general procedure in which $\mathrm{CuCl}$ (584.3 mg, $5.90 \mathrm{mmol})$, bipy (1844.2 mg, $11.81 \mathrm{mmol})$ and water:ethanol mixture (160 mL, 1:1, v/v) were used. Here, the monomer NaSS (20 g, $97 \mathrm{mmol})$ was added to the second round-bottom flask together with 3 low-density activated PES-Cl membranes.

FT-IR spectrum (cm-1): 3096 (C-H), $3069(\mathrm{C}-\mathrm{H}), 1577$ (C=C $\left.\mathrm{C}_{\text {arom }}\right), 1485$ (C=Carom $), 1297$ $(\mathrm{S}=\mathrm{O}), 1237(\mathrm{C}-\mathrm{O}), 1148(\mathrm{~S}=\mathrm{O}), 1072(\mathrm{C}-\mathrm{O}), 1035\left(\mathrm{SO}_{3}\right)$.

\subsection{Synthesis of grafted mPVI membranes via SI-ATRP from PES-Cl membrane}

Grafted mPVI membranes were synthesized in accordance with the general procedure in which $\mathrm{CuCl}$ (1232.0 mg, $12.44 \mathrm{mmol})$, bipy (4316.7 mg, $27.64 \mathrm{mmol}), \mathrm{VI}$ (60 mL, 
$662 \mathrm{mmol})$, water:ethanol mixture $(60 \mathrm{~mL}, 1: 1)$ and 6 low-density activated PES-Cl membranes were used.

FT-IR spectrum (cm-1): 3096 (C-H), $3069(\mathrm{C}-\mathrm{H}), 1577$ (C=C $\left.\mathrm{C}_{\text {arom }}\right), 1485$ (C=Carom), 1297 $(\mathrm{S}=\mathrm{O}), 1237(\mathrm{C}-\mathrm{O}), 1148$ (S=O), $1072(\mathrm{C}-\mathrm{O})$.

\subsection{Synthesis of quarternized mPVIq membrane from grafted mPVI membrane}

A round-bottom flask was charged with a magnetic stirrer, 9 grafted mPVI membranes (3 pieces of each polymerization time), ethanol $(90 \mathrm{~mL})$ and $\mathrm{BuBr}(10 \mathrm{~mL}, 93.13 \mathrm{mmol})$. The flask was heated to $60^{\circ} \mathrm{C}$ and the reaction took place under reflux overnight. The quarternized mPVIq membranes were washed with ethanol and stored in water at $5{ }^{\circ} \mathrm{C}$ until further use.

FT-IR spectrum (cm-1): $3096(\mathrm{C}-\mathrm{H}), 3069(\mathrm{C}-\mathrm{H}), 1577\left(\mathrm{C}=\mathrm{C}_{\mathrm{arom}}\right), 1485\left(\mathrm{C}=\mathrm{C}_{\text {arom }}\right), 1297$ $(\mathrm{S}=\mathrm{O}), 1237(\mathrm{C}-\mathrm{O}), 1148(\mathrm{~S}=\mathrm{O}), 1072(\mathrm{C}-\mathrm{O})$.

\subsection{Membrane modules preparation}

Single-fiber modules with $5 \mathrm{~cm}^{2}$ effective membrane area $(20 \mathrm{~cm}$ effective length of the fiber) were fabricated in order to test membrane properties. A membrane was immersed either in glycerol for $1 \mathrm{~h}$ (to protect the pores from collapsing), or ethanol for $2 \mathrm{~h}$ (to facilitate pore collapse). The glycerol excess on the fiber surface was removed with a paper towel before the membrane was installed in the module. The ethanol-treated membranes were allowed to dry in air for $2 \mathrm{~h}$ before being installed in the modules. Both the protected (glycerol-treated) and the collapsed (ethanol-treated) membranes were inserted into polyethylene tubes connected with Festo T-shape push-in fittings (for permeate outlet). The ends were sealed with epoxy glue (Bison $2 \mathrm{~K}$ polyurethane adhesive expert) to separate the 
feed inlet and the permeate outlet. A photograph of the prepared module is shown in Figure 1.

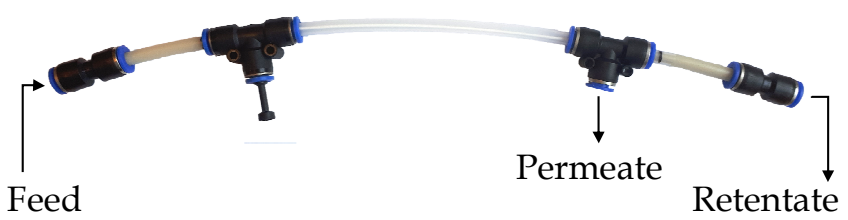

Figure 1: Single-fiber membrane module with feed inlet, permeate and retentate outlets marked.

2.10Membrane properties test setup - Water flux and rejection of $\mathrm{NaCl}, \mathrm{MgSO}_{4}$ and calcein

The modules were connected in parallel to a micro gear pump (LongerPump ${ }^{\mathrm{TM}}$ WT3000-1JB) and a tank containing a single-solute feed solution (20 L) - NaCl (58 Da, 500 ppm), $\mathrm{MgSO}_{4}$ (120 Da, 2000 ppm), or calcein (623 Da, 3.1 ppm), respectively. Linear velocity of the feed solution through the membrane modules was fixed to $21-25 \mathrm{~m} \mathrm{~min}^{-1}$. Retentate was recirculated back to the feed tank. Pressure on both the feed and the retentate side was recorded and was controlled by a valve on the retentate side. The average pressure of the two was set to 3 bar. The permeate was collected into separate volumetric cylinders until approximately $15 \mathrm{~mL}$ was collected. Solute concentration in the permeate was quantified by conductivity $\left(\mathrm{NaCl}, \mathrm{MgSO}_{4}\right)$ or fluorescence (calcein). Each measurement was done three times. The setup scheme is shown in Figure 2. 


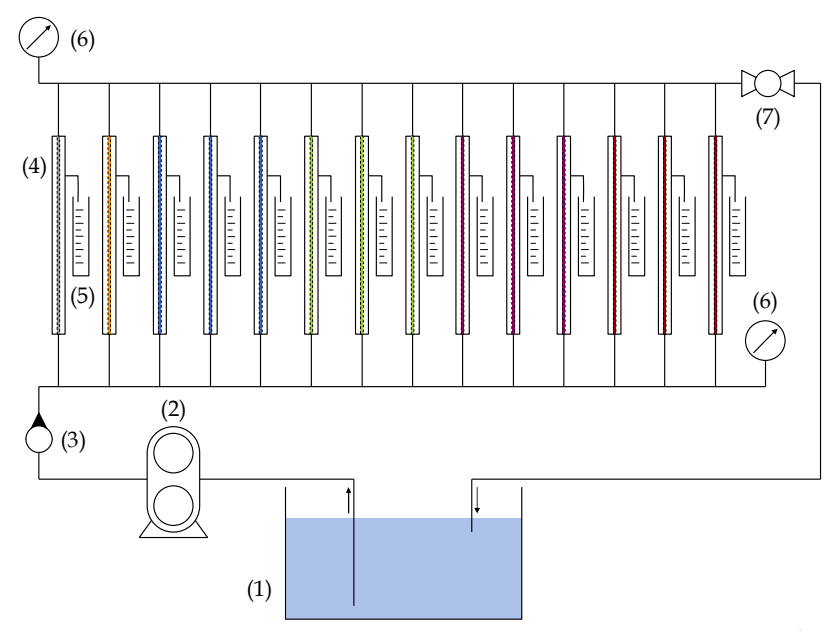

Figure 2: Scheme of the membrane properties test setup. (1) Feed tank, (2) micro gear pump, (3) rotameter, (4) membrane module, (5) volumetric cylinder, (6) pressure gauge and (7) ball valve.

The water flux J was calculated as

$$
J=\frac{V}{S t}
$$

where $V$ is the volume of the permeate (L), $S$ is the effective membrane area $\left(\mathrm{m}^{2}\right)$ and $t$ is the collection time (h).

The solute rejection $R$ was calculated as

$$
R=\left(1-\frac{X_{\mathrm{p}}}{X_{\mathrm{f}}}\right) 100 \%
$$

where $X_{\mathrm{p}}$ and $X_{\mathrm{f}}$ are either conductivities or fluorescence intensities of permeate and feed, respectively.

\section{Results and discussion}

To investigate the impact of different surface chemistries on pore collapse and rejection, a range of different polymer-grafted membranes was prepared (see Figure 3). 


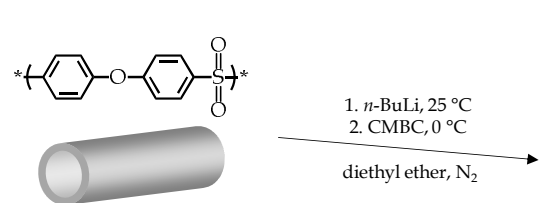

PES

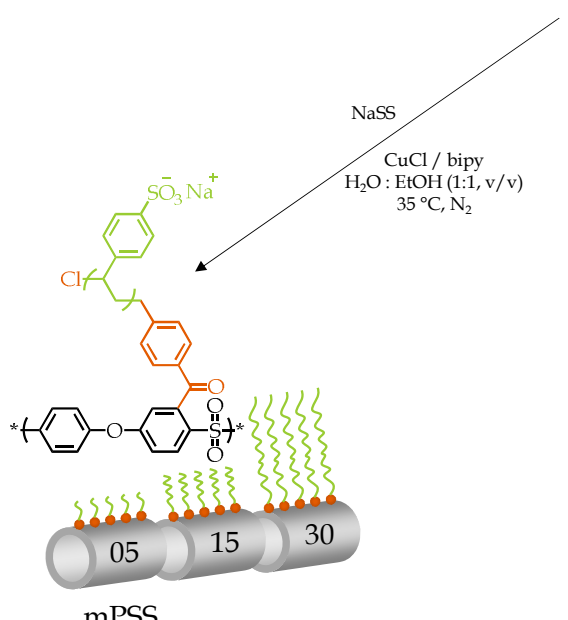

mPSS
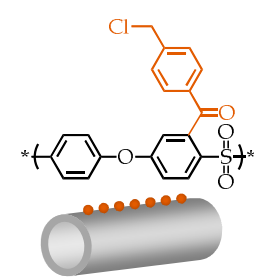

PES-Cl

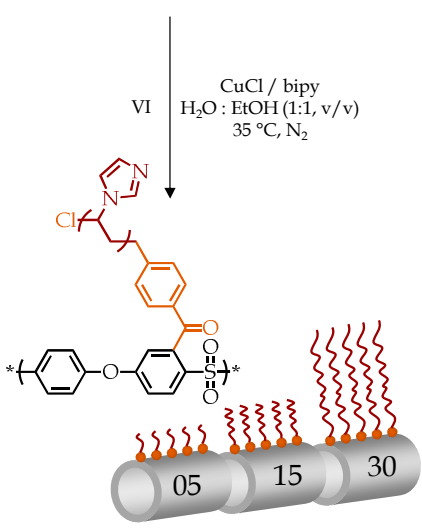

mPVI
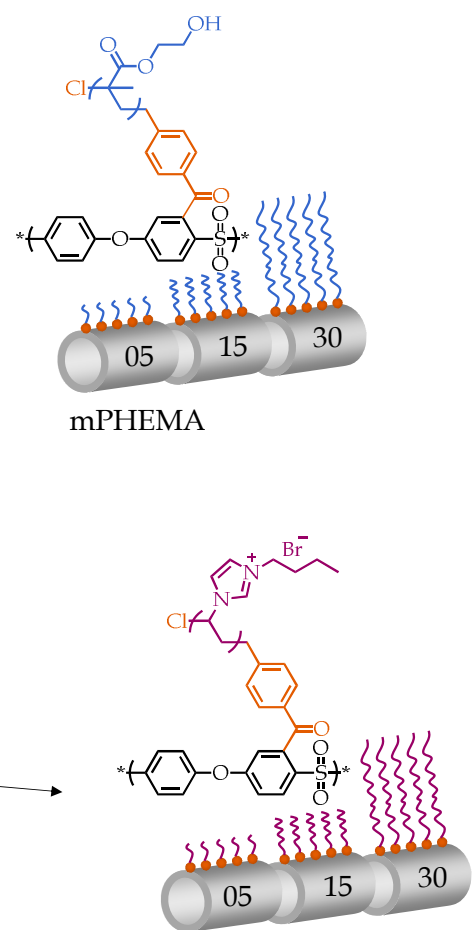

mPVIq

Figure 3: Reaction scheme for the membrane surface modifications. In the first step, the original PES membrane underwent heterogeneous ortholithiation and subsequent acylation to form the activated PES-Cl membrane. Subsequently, SI-ATRP with 3 polymerization times $(5,15$ and $30 \mathrm{~min})$ was performed to prepare grafted mPHEMA, mPSS and mPVI membranes. Finally, the mPVI membranes were converted to poly(ionic liquid) membranes through quarternization using 1-bromobutane.

\subsection{Synthesis of activated, grafted and quarternized membranes}

The original hollow-fiber membrane was first activated by heterogeneous ortholithiation and subsequent acylation to introduce benzyl chloride groups that serve as ATRP initiators. Depending on the concentration of reagents, this step results in a specific grafting density [35]. Here we aimed at low grafting density in order to prevent pore blocking. Thereafter, surface-initiated ATRP was performed from the activated membranes for short reaction times $(5,15$ and $30 \mathrm{~min})$ to achieve different chain lengths of the grafted polymers. Three monomers were chosen - HEMA to increase hydrophilicity of the surface, NaSS to introduce 
charged groups and VI to increase hydrophilicity and to introduce polyionic liquid to the surface by post-polymerization quarternization.

These low grafting density modifications target very thin surface layers, which are not easily observed by traditional analytical methods, but would be expected to result in improved membrane properties. Nevertheless, FT-IR spectroscopy and XPS were used to investigate the chemical compositions of the prepared surfaces as shown in Figure 4 and

Table 1.

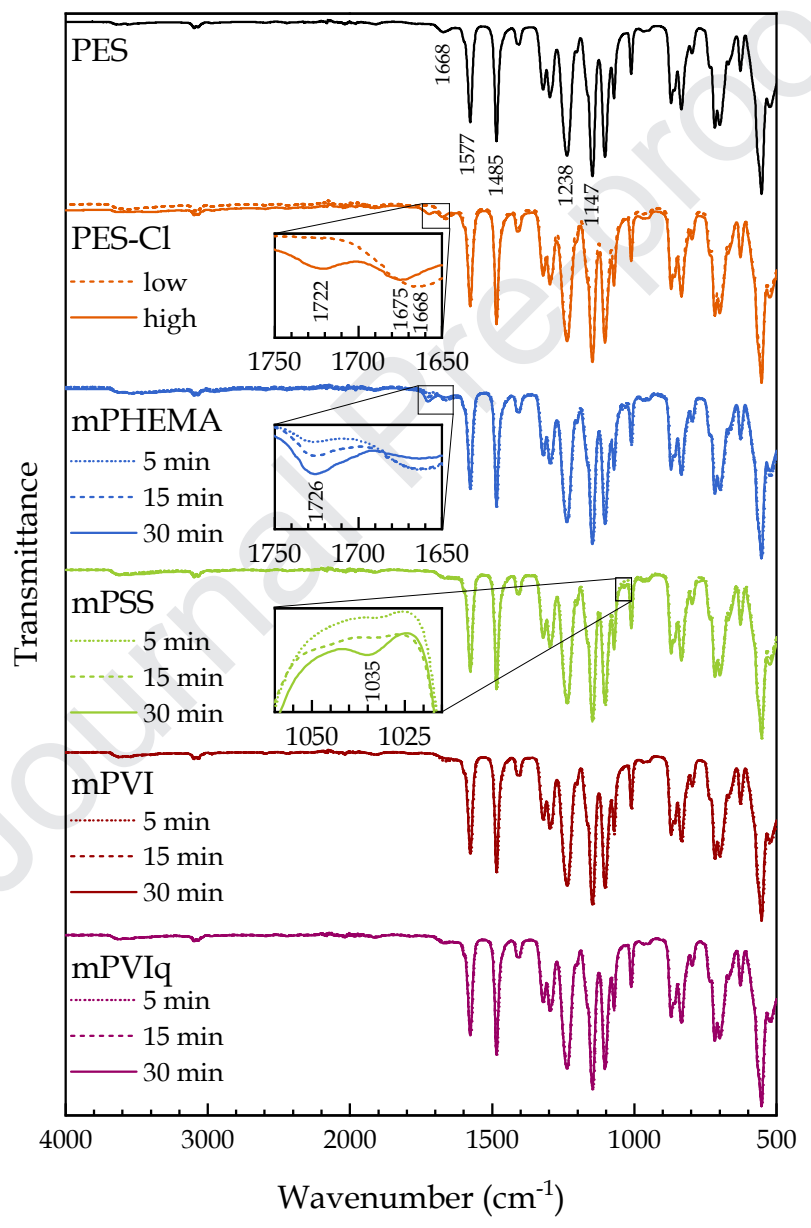

Figure 4: Normalized FT-IR spectra of original (glycerol removed) PES, low- and high-density activated PES-Cl, grafted mPHEMA, mPSS and mPVI, and quarternized mPVIq membranes with polymerization times 5, 15 and $30 \mathrm{~min}$. 
The first synthetic step leading to the activated PES-Cl membrane results in two new bands at $1675 \mathrm{~cm}^{-1}$ and $1722 \mathrm{~cm}^{-1}$ in the FT-IR spectrum (Figure 4, PES-Cl high). The band at $1675 \mathrm{~cm}^{-1}$ is assigned to a carbonyl stretch in conjugated ketones originating from the benzophenone part of the activated PES-Cl membrane as expected. The second carbonyl stretch at $1722 \mathrm{~cm}^{-1}$ is assigned to an ester group in phenyl benzoates that can be formed by hydrolysis of the ether link in the PES backbone. Therefore, both introduced functionalities (ketone and ester) are covalent modifications. In order to obtain modified membranes with low grafting density, concentrations of the reagents in the activation step were decreased. This resulted in a lower degree of modification, which could no longer be confirmed by FT-IR (Figure 4, PES-Cl low), but was confirmed by XPS as discussed later.

After SI-ATRP, FT-IR spectrum of the grafted mPHEMA membrane shows a carbonyl stretch at $1726 \mathrm{~cm}^{-1}$ coming from the surface-grafted polymer side chains. FT-IR spectrum of the grafted mPSS membrane shows a weak sulfonate stretch at $1035 \mathrm{~cm}^{-1}$. In both cases (mPHEMA and mPSS), the assigned bands increase in intensity with increasing polymerization time showing control over of the chain length by adjusting the polymerization time. Grafting and subsequent quarternization in the mPVI into mPVIq membranes could not be conclusively confirmed by FT-IR spectroscopy, due to the similar chemical compositions of these surfaces.

The very subtle changes in FT-IR spectra after modifications compared to the pristine PES membrane correlate well with the targeted low degree of surface functionalization. XPS analysis corroborated the polymer grafting via SI-ATRP, as shown in Table 1.

In general, the atomic compositions of all the modified membranes are very similar to that of the original PES membrane (Table 1). This confirms that the intended very thin layer (units of nm) of grafted polymer was introduced on the membrane. After the activation reaction, chlorine from the ATRP initiator could be detected and the composition of the membrane changed in agreement with the predicted trends (see Table 1 in Supporting 
Information). The atomic compositions of the polymer grafted membranes (mPHEMA, mPSS, mPVI and mPVIq) were compared with the composition of the activated PES-Cl membrane, which confirms that the grafting took place. Increase in oxygen content is observed in the mPHEMA grafted membrane; mPSS membrane gives a sulfur content increase; and both mPVI and mPVIq membranes show slightly higher nitrogen content. Halogens were observed on the surfaces after grafting. However, the concentrations are generally lower than theoretically predicted, which was attributed to possible uncontrolled termination reactions as well as loss of halogens during analysis, as has also been observed by others [37].

Table 1: XPS data of the original PES, low-density activated PES-Cl, grafted mPHEMA, mPSS and mPVI, and quarternized mPVIq membranes.

\begin{tabular}{lccccc}
\hline \multirow{2}{*}{ Name } & C 1s & N 1s & O 1s & S 2p & Cl 2p \\
\cline { 2 - 6 } & \multicolumn{5}{c}{ (atom \%) } \\
\hline PES & $72.4 \pm 0.4$ & $2.8 \pm 0.4$ & $19.4 \pm 0.2$ & $5.4 \pm 0.1$ & - \\
PES-Cl & $74.5 \pm 0.2$ & $2.4 \pm 0.2$ & $17.1 \pm 0.2$ & $2.9 \pm 0.1$ & $3.1 \pm 0.2$ \\
\hline mPHEMA05 & $71.6 \pm 0.3$ & $2.3 \pm 0.2$ & $21.4 \pm 0.3$ & $3.6 \pm 0.2$ & $1.1 \pm 0.0$ \\
mPHEMA15 & $69.8 \pm 0.3$ & $2.9 \pm 0.4$ & $23.5 \pm 0.4$ & $2.9 \pm 0.2$ & $0.9 \pm 0.0$ \\
mPHEMA30 & $71.4 \pm 0.2$ & $1.9 \pm 0.2$ & $22.1 \pm 0.3$ & $4.6 \pm 0.2$ & - \\
\hline mPSS05 & $72.9 \pm 0.3$ & $3.3 \pm 0.1$ & $18.1 \pm 0.3$ & $5.8 \pm 0.1$ & - \\
mPSS15 & $72.5 \pm 0.3$ & $3.3 \pm 0.2$ & $18.5 \pm 0.2$ & $5.7 \pm 0.1$ & - \\
mPSS30 & $70.4 \pm 0.5$ & $4.5 \pm 0.1$ & $19.7 \pm 0.5$ & $5.4 \pm 0.1$ & - \\
\hline mPVI05 & $73.6 \pm 0.4$ & $2.3 \pm 0.6$ & $18.5 \pm 0.2$ & $5.5 \pm 0.1$ & - \\
mPVI15 & $71.9 \pm 0.8$ & $3.9 \pm 0.7$ & $18.9 \pm 0.6$ & $5.3 \pm 0.3$ & - \\
mPVI30 & $72.5 \pm 0.5$ & $3.8 \pm 0.8$ & $18.6 \pm 0.1$ & $5.1 \pm 0.3$ & - \\
\hline mPVIq05 & $70.9 \pm 0.4$ & $3.4 \pm 0.3$ & $19.8 \pm 0.2$ & $4.8 \pm 0.1$ & $1.0 \pm 0.1$ \\
mPVIq15 & $70.5 \pm 0.5$ & $3.9 \pm 0.4$ & $19.6 \pm 0.1$ & $4.9 \pm 0.2$ & $1.1 \pm 0.5$ \\
mPVIq30 & $70.7 \pm 0.6$ & $4.4 \pm 0.3$ & $19.4 \pm 0.4$ & $4.6 \pm 0.1$ & $0.9 \pm 0.4$ \\
\hline & & & & & \\
\hline
\end{tabular}




\subsection{Controlled pore collapse and membrane properties}

Before installing the membranes in the single-fiber modules, the modified membranes were either treated with glycerol to protect the pores, or else treated with ethanol to collapse the membrane by subsequent drying in air. Water flux data of protected and collapsed membranes are shown in Figure 5.
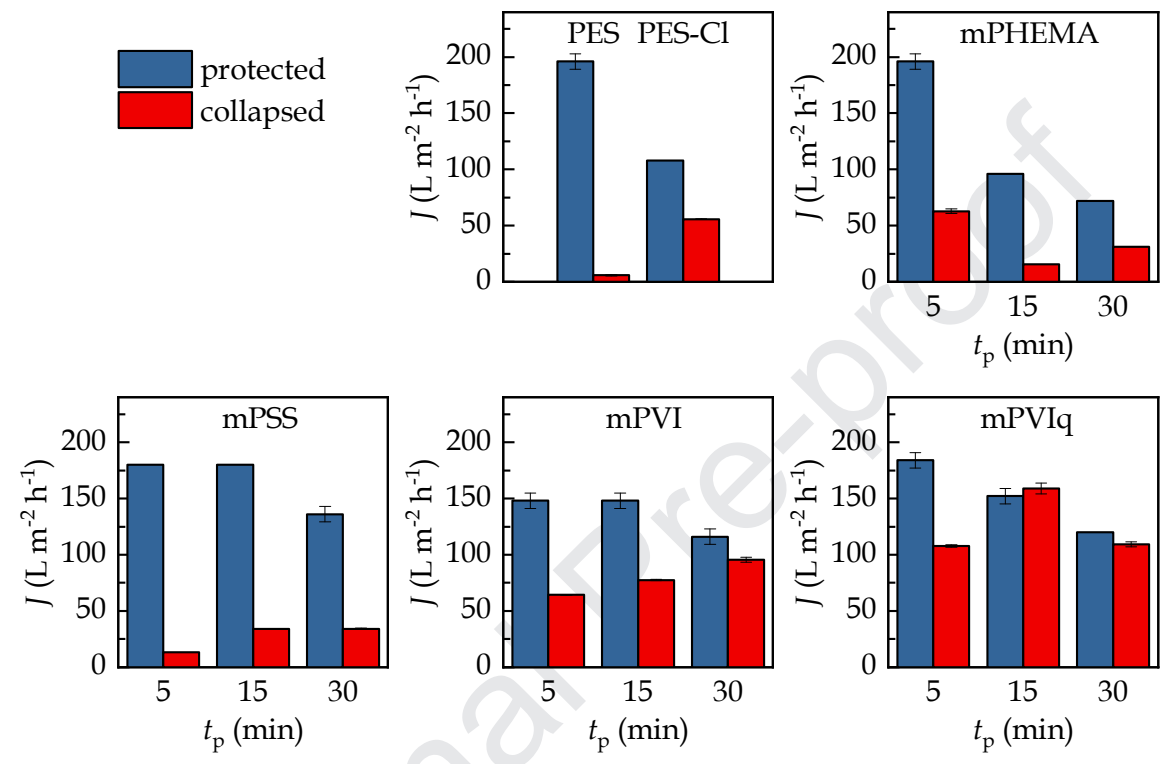

Figure 5: Water flux J at 3 bar of the original PES, low-density activated PES-Cl, grafted mPHEMA, mPSS, mPVI and quarternized mPVIq membranes (protected and collapsed) with increasing polymerization time $t_{\mathrm{p}}$.

When the pores are protected by glycerol, the impact of the surface modifications on the membrane water flux can be observed (Figure 5). After activation (PES vs. PES-Cl), the water flux drops to half of its reference value, which is attributed to the change in surface chemistry and bulkiness of the modification. The flux is restored after grafting for a short polymerization time (5 min). In all cases, the water flux of the grafted and the quarternized membranes (mPHEMA, mPSS, mPVI, mPVIq) decreases with increasing polymerization time, as the increasing chain length of the grafted polymer blocks the pores to a larger extent [28,38-40]. Quarternization (mPVI vs. mPVIq) leads to an increased water flux at all polymerization times, which is ascribed to the increased ionic liquid character of the 
quarternized chains increasing hydrophilicity of the system and stronger repulsion forces between the quarternized polymers as compared to the pure polyvinylimidazole chains. In general, all modified membranes maintain high water flux compared to the PES membrane as long as the pores are protected from collapse.

Once the membranes are dried, causing the pore collapse, the membranes noticeably change their behavior (Figure 5). As expected, the majority of the collapsed membranes show significantly reduced water flux as compared to their glycerol-protected counterparts. For the collapsed systems, the water flux increases with increasing polymerization time of the grafted polymers (mPSS and mPVI). This is ascribed to the polymer grafts on the surface controlling the extent of PES membrane collapse. Thus, with increasing polymerization time, the extent of pore collapse decreases, leading to higher water flux. In the case of the quarternized mPVIq membranes, due to the strong repulsion forces between charged grafts, the grafted surface layer very efficiently suppresses the pore collapse already after a short polymerization time. Specifically, the quarternized mPVIq after 15 min of polymerization, effectively protects the membrane from collapse and the water flux of the protected and the collapsed membrane is very similar. Moreover, the water flux in this case remains high in both cases, underlining that this could be a solution in cases where the inevitable pore collapse cannot be prevented (exposure to air or repeated drying out of membranes). Prolonged polymerization time leads to a drop in water flux for both protected and collapsed membranes, in line with the increased chain length of the surface-grafted polymers.

In addition, the influence of the surface modifications and subsequent pore collapse on solute rejection was studied. Overall, rejection of the two salts $\left(\mathrm{NaCl}\right.$ and $\left.\mathrm{MgSO}_{4}\right)$ is very low (see Figure 1 in Supporting Information). Nevertheless, all rejection data show the same trends in terms of polymerization time before and after pore collapse, independent of the 
solute. Therefore, the effects on solute rejection were exemplified using calcein as shown in Figure 6.
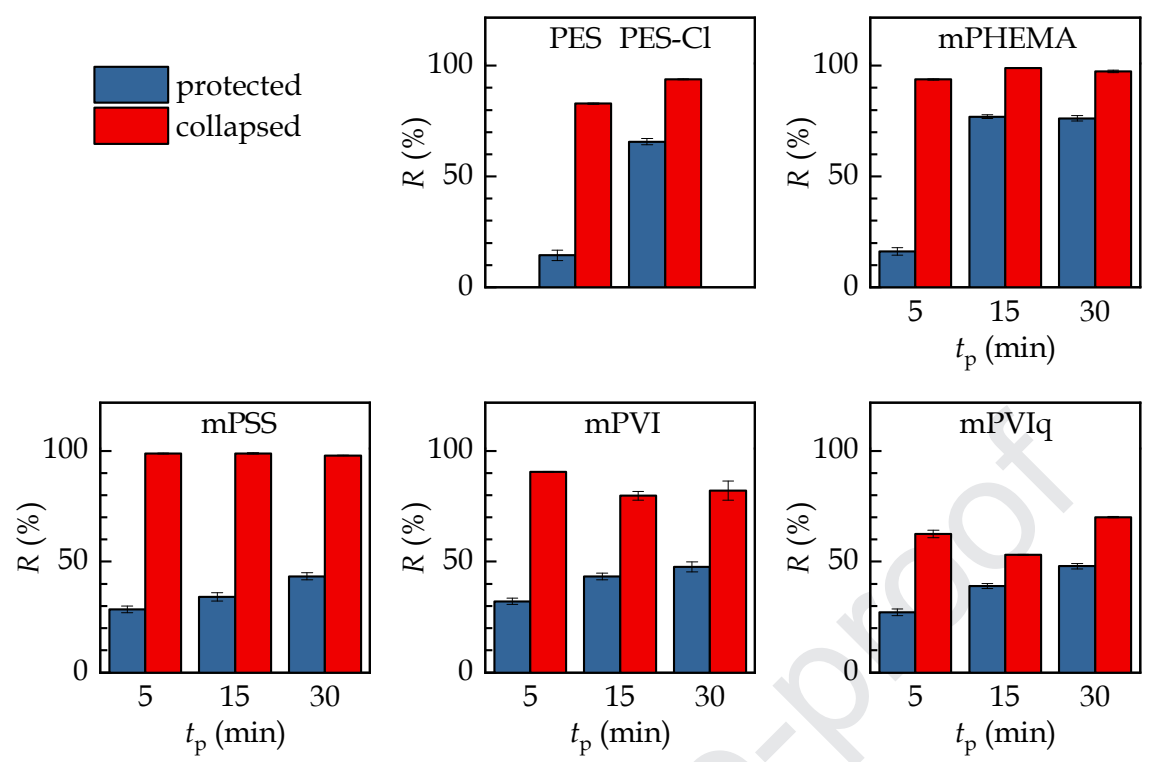

Figure 6: Calcein rejection $R$ at 3 bar of the original PES, low-density activated PES-Cl, grafted mPHEMA, mPSS, mPVI and quarternized mPVIq membranes with increasing polymerization time $t_{\mathrm{p}}$.

As expected, calcein rejection of the protected PES membrane is low (Figure 6). After the chemical modifications, the rejection increases even in the glycerol-protected systems. With increasing polymerization time, the calcein rejection increases in all cases of the glycerolprotected membranes.

After allowing the pores to collapse, calcein rejection of the PES membrane rises to $82.8 \pm 0.2 \%$ and all the grafted membranes (mPHEMA, mPSS and mPVI) reach almost full calcein rejection (Figure 6) shifting them to a low-pressure nanofiltration mode. Rejection in the quarternized mPVIq membranes does not increase as dramatically as in the case of grafted membranes, since the pore collapse here is efficiently suppressed by the specific surface chemistry.

By altering the surface chemistry and facilitating pore collapse, the rejection-to-water flux ratio can be optimized as shown in Figure 7. 


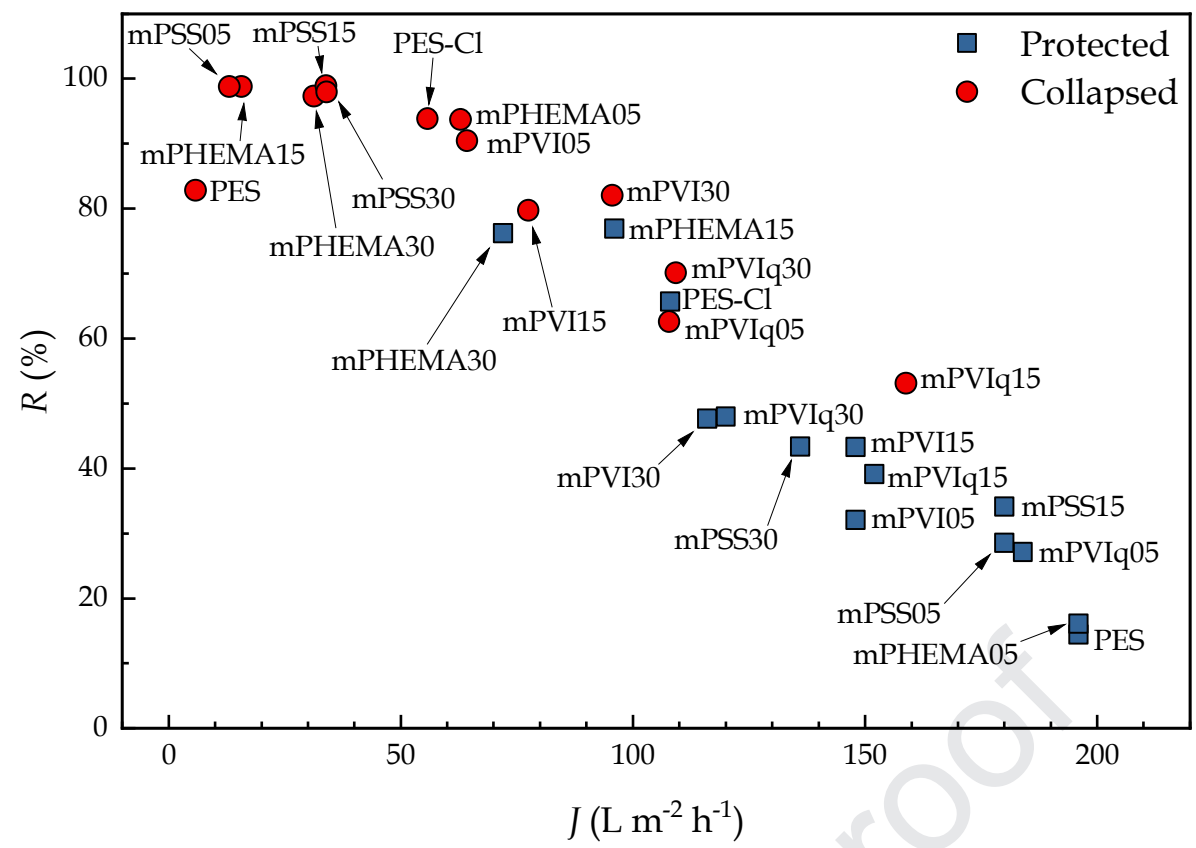

Figure 7: Calcein rejection $R$ versus water flux $J$ at 3 bar of all the membranes.

For instance, the protected mPHEMA membrane grafted for 15 min gives a significantly increased rejection $(76.9 \pm 0.9 \%)$ while still exhibiting an acceptable water flux $(96.0 \pm 0.5 \mathrm{~L}$ $\left.\mathrm{m}^{-2} \mathrm{~h}^{-1}\right)$, compared to the protected PES membrane. A different example to note is the protected $\mathrm{mPVI}$ membrane grafted for $15 \mathrm{~min}$, where the water flux is largely maintained $\left(148 \pm 8 \mathrm{~L} \mathrm{~m}^{-2} \mathrm{~h}^{-1}\right)$ and rejection still noticeably increased (43.3 $\left.\pm 1.6 \%\right)$. Overall, these two examples show that the surface modification alone is sufficient to tailor the membrane properties. It is clearly seen in Figure 7 that most of the collapsed modified membranes greatly outcompete the collapsed PES membrane in terms of both rejection and water flux, showing the beneficial effect of surface modification on membrane properties.

\subsection{Scanning electron microscopy}

Membrane pore collapse upon drying was investigated by environmental SEM, where the wet membrane samples were allowed to dry inside the instrument. It was attempted, in order to see if we could observe a direct change of the membrane structure during collapse. 
However, it was not possible to get enough contrast before collapse to actually determine a change in surface porosity (see SI-Figure 2). When the pores are protected, the SEM pictures show low contrast as can be seen in the glycerol-treated membrane (SI-Figure 3), and it is therefore unfortunately not possible to observe the specific surface structure without collapse. After washing the membrane to remove glycerol and allowing it to dry out, the contrast increases and pores can be observed more clearly. For the modified membranes, small clusters in the pores on the shell side (SI-Figure 4) as well as on the lumen side (Figure 8b-e) are clearly identified in all cases, confirming that grafting has taken place. The micrographs at longer polymerization times also show these structures (see SI-Figures 5-7), confirming that the polymerizations took place. However, it was not possible directly to correlate longer polymerization times and the observed surface modifications to the changes in membrane permeability from the micrographs. 


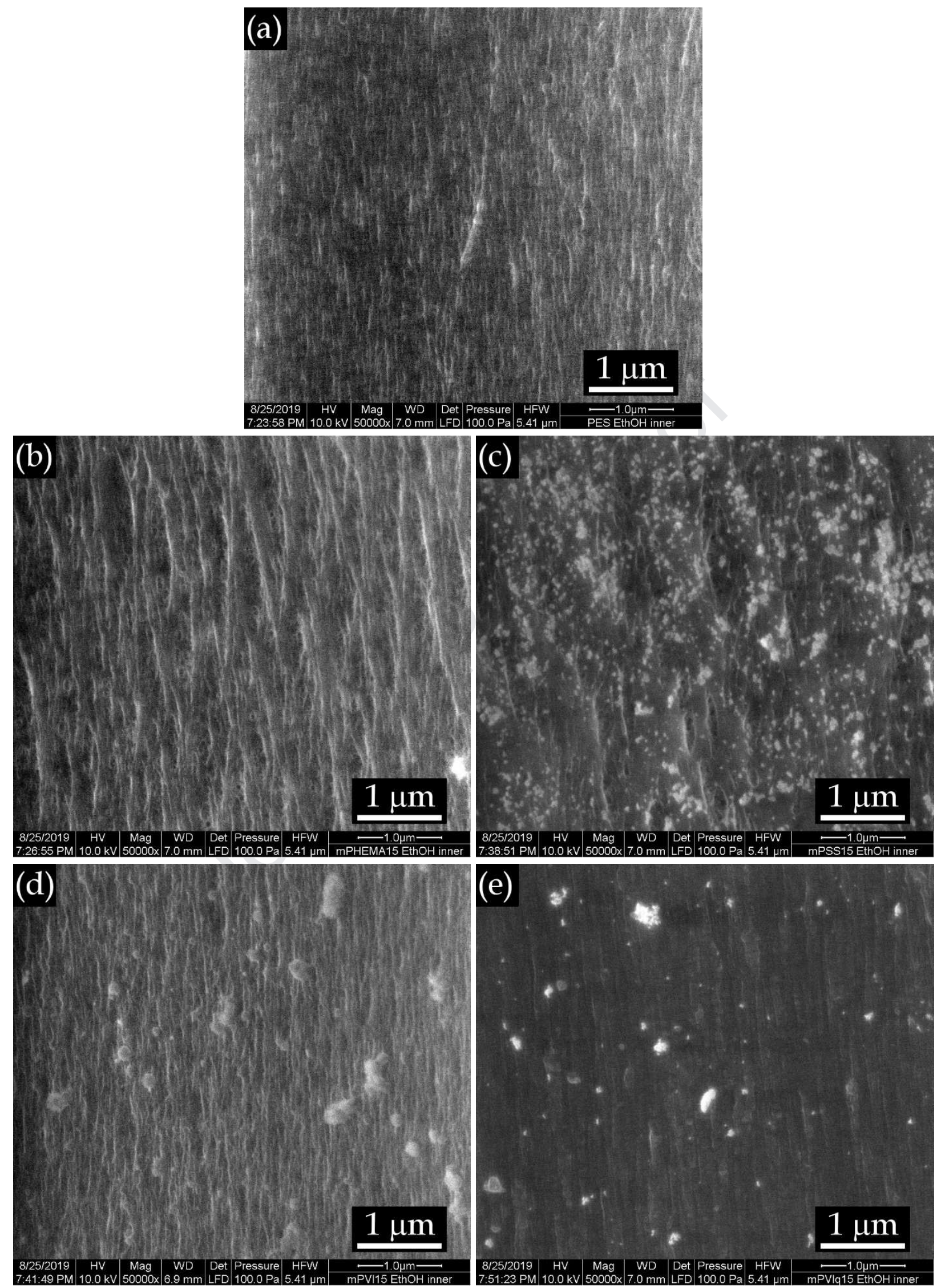

Figure 8: Scanning electron microphotographs of the lumen surface of (a) the PES membrane, and the membranes grafted for 15 min with (b) mPHEMA, (c) mPSS, (d) mPVI and (e) mPVIq. 


\section{Conclusions}

Ultrafiltration hollow-fiber PES membranes were for the first time surface-modified via SI-ATRP. Membranes with a range of surface chemistries were prepared and tested in single-fiber membrane modules. The polymer grafting could be used to control the water flux and solute rejection characteristics of the membranes. With increasing polymerization time of the grafted polymers, water flux decreases and rejection increases when the membranes are used as prepared and protected with glycerol. Selective membrane pore collapse could be exploited to obtain higher rejection. Here, increasing the chain length of the grafted polymer results in a water flux increase at the cost of a decrease in rejection. The chemical nature of the grafted polymer is directly reflected in the water flux-to-rejection ratio and the extent of pore collapse.

We have here shown how intentional pore collapse can be used to achieve membranes with higher rejection and controlled water flux. This provides a platform for tailoring membrane properties to specific applications in terms of rejection and water flux, which greatly extends the application range of ultrafiltration membranes.

\section{Acknowledgements}

The authors wish to thank the Danish Council for Independent Research for financial support through grant no. DFF - 7017-00109.

\section{References}

[1] T.A. Tweddle, O. Kutowy, W.L. Thayer, S. Sourirajan, Polysulfone ultrafiltration membranes, Ind. Eng. Chem. Prod. Res. Dev. 22 (1983) 320-326. doi:10.1021/i300010a030.

[2] S. Mokhtari, A. Rahimpour, A.A. Shamsabadi, S. Habibzadeh, M. Soroush, Enhancing performance and surface antifouling properties of polysulfone ultrafiltration membranes with salicylate-alumoxane nanoparticles, Appl. Surf. Sci. 393 (2017) 93-102. doi:10.1016/j.apsusc.2016.10.005. 
nanofiltration membrane modified with $\mathrm{TiO} 2$ nanoparticles for better performance and surface properties, J. Ind. Eng. Chem. 18 (2012) 1398-1405. doi:10.1016/j.jiec.2012.01.041.

[4] A. Rahimpour, M. Jahanshahi, N. Mortazavian, S.S. Madaeni, Y. Mansourpanah, Preparation and characterization of asymmetric polyethersulfone and thin-film composite polyamide nanofiltration membranes for water softening, Appl. Surf. Sci. 256 (2010) 1657-1663. doi:10.1016/j.apsusc.2009.09.089.

[5] M.S. Eisen, R. Semiat, N. Vainrot, Polysulfone polymers and membranes for reverse osmosis, nanofiltration and ultrafiltration, 2015. https://www.google.com/patents/US8944257.

[6] H.M. Park, K.Y. Jee, Y.T. Lee, Preparation and characterization of a thin-film composite reverse osmosis membrane using a polysulfone membrane including metal-organic frameworks, J. Memb. Sci. 541 (2017) 510-518. doi:10.1016/j.memsci.2017.07.034.

[7] M. Ulbricht, Advanced functional polymer membranes, Polymer (Guildf). 47 (2006) 2217-2262. doi:10.1016/j.polymer.2006.01.084.

[8] H. Toiserkani, G. Yilmaz, Y. Yagci, L. Torun, Functionalization of Polysulfones by Click Chemistry, Macromol. Chem. Phys. 211 (2010) 2389-2395. doi:10.1002/macp.201000245.

[9] A. Higuchi, H. Koga, T. Nakagawa, Surface-modified polysulfone hollow fibers. IV. Chloromethylated fibers and their derivatives, J. Appl. Polym. Sci. 46 (1992) 449-457. doi:10.1002/app.1992.070460310.

[10] L. Breitbach, E. Hinke, E. Staude, Heterogeneous functionalizing of polysulfone membranes, Macromol. Mater. Eng. 184 (1991) 183-196. doi:10.1002/apmc.1991.051840116.

[11] M. Ulbricht, M. Riedel, Ultrafiltration membrane surfaces with grafted polymer "tentacles": preparation, characterization and application for covalent protein binding, Biomaterials. 19 (1998) 1229-1237. doi:10.1016/S01429612(98)00029-5.

[12] J. Pieracci, J. V Crivello, G. Belfort, Photochemical modification of 10kDa polyethersulfone ultrafiltration membranes for reduction of biofouling, J. Memb. Sci. 156 (1999) 223-240. doi:10.1016/S0376-7388(98)00347-0.

[13] J. Pieracci, D.W. Wood, J. V. Crivello, G. Belfort, UV-Assisted Graft Polymerization of N -vinyl-2-pyrrolidinone onto Poly(ether sulfone) Ultrafiltration Membranes: Comparison of Dip versus Immersion Modification Techniques, Chem. Mater. 12 (2000) 2123-2133. doi:10.1021/cm9907864.

[14] C.J. Fristrup, K. Jankova, S. Hvilsted, Surface-initiated atom transfer radical polymerization - a technique to develop biofunctional coatings, Soft Matter. 5 (2009) 4623. doi:10.1039/b821815c.

[15] R. Barbey, L. Lavanant, D. Paripovic, N. Schüwer, C. Sugnaux, S. Tugulu, H.-A. Klok, Polymer Brushes via SurfaceInitiated Controlled Radical Polymerization: Synthesis, Characterization, Properties, and Applications, Chem. Rev. 109 (2009) 5437-5527. doi:10.1021/cr900045a.

[16] J.O. Zoppe, N.C. Ataman, P. Mocny, J. Wang, J. Moraes, H.-A. Klok, Surface-Initiated Controlled Radical Polymerization: State-of-the-Art, Opportunities, and Challenges in Surface and Interface Engineering with Polymer Brushes, Chem. Rev. 117 (2017) 1105-1318. doi:10.1021/acs.chemrev.6b00314.

[17] A.E. Daugaard, K. Jankova, S. Hvilsted, Poly(lauryl acrylate) and poly(stearyl acrylate) grafted multiwalled carbon 
nanotubes for polypropylene composites, Polymer (Guildf). 55 (2014) 481-487. doi:10.1016/j.polymer.2013.12.031.

[18] A.E. Daugaard, K. Jankova, J. Bøgelund, J.K. Nielsen, S. Hvilsted, Novel UV initiator for functionalization of multiwalled carbon nanotubes by atom transfer radical polymerization applied on two different grades of nanotubes, J. Polym. Sci. Part A Polym. Chem. 48 (2010) 4594-4601. doi:10.1002/ pola.24257.

[19] L. Sun, J. Dai, G.L. Baker, M.L. Bruening, High-Capacity, Protein-Binding Membranes Based on Polymer Brushes Grown in Porous Substrates, Chem. Mater. 18 (2006) 4033-4039. doi:10.1021/cm060554m.

[20] N. Singh, Z. Chen, N. Tomer, S.R. Wickramasinghe, N. Soice, S.M. Husson, Modification of regenerated cellulose ultrafiltration membranes by surface-initiated atom transfer radical polymerization, J. Memb. Sci. 311 (2008) 225-234. doi:10.1016/j.memsci.2007.12.036.

[21] J.-S. Wang, K. Matyjaszewski, Controlled/“living" radical polymerization. atom transfer radical polymerization in the presence of transition-metal complexes, J. Am. Chem. Soc. 117 (1995) 5614-5615. doi:10.1021/ja00125a035.

[22] K. Matyjaszewski, Controlled radical polymerization, Curr. Opin. Solid State Mater. Sci. 1 (1996) 769-776. doi:10.1016/S1359-0286(96)80101-X.

[23] K. Matyjaszewski, J. Xia, Atom Transfer Radical Polymerization, Chem. Rev. 101 (2001) 2921-2990. doi:10.1021/cr940534g.

[24] L. Li, G. Yan, J. Wu, Modification of polysulfone membranes via surface-initiated atom transfer radical polymerization and their antifouling properties, J. Appl. Polym. Sci. 111 (2009) 1942-1946. doi:10.1002/app.29204.

[25] T. Xiang, L.-S. Zhang, R. Wang, Y. Xia, B.-H. Su, C.-S. Zhao, Blood compatibility comparison for polysulfone membranes modified by grafting block and random zwitterionic copolymers via surface-initiated ATRP, J. Colloid Interface Sci. 432 (2014) 47-56. doi:10.1016/j.jcis.2014.06.044.

[26] H.-B. Dong, Y.-Y. Xu, Z. Yi, J.-L. Shi, Modification of polysulfone membranes via surface-initiated atom transfer radical polymerization, Appl. Surf. Sci. 255 (2009) 8860-8866. doi:10.1016/j.apsusc.2009.06.075.

[27] J. Qiu, Y. Zhang, Y. Shen, Y. Zhang, H. Zhang, J. Liu, Hydrophilic modification of microporous polysulfone membrane via surface-initiated atom transfer radical polymerization of acrylamide, Appl. Surf. Sci. 256 (2010) 3274-3280. doi:10.1016/j.apsusc.2009.12.018.

[28] W.W. Yue, H.J. Li, T. Xiang, H. Qin, S.D. Sun, C.S. Zhao, Grafting of zwitterion from polysulfone membrane via surface-initiated ATRP with enhanced antifouling property and biocompatibility, J. Memb. Sci. 446 (2013) 79-91. doi:10.1016/j.memsci.2013.06.029.

[29] M.D. Guiver, G.P. Robertson, M. Yoshikawa, C.M. Tam, Functionalized Polysulfones: Methods for Chemical Modification and Membrane Applications, in: 1999: pp. 137-161. doi:10.1021/bk-2000-0744.ch010.

[30] M.D. Guiver, S. Croteau, J.D. Hazlett, O. Kutowy, Synthesis and characterization of carboxylated polysulfones, Br. Polym. J. 23 (1990) 29-39. doi:10.1002/pi.4980230107.

[31] A. Higuchi, N. Iwata, M. Tsubaki, T. Nakagawa, Surface-modified polysulfone hollow fibers, J. Appl. Polym. Sci. 36 (1988) 1753-1767. doi:10.1002/app.1988.070360804.

[32] A. Higuchi, K. Shirano, M. Harashima, B.O. Yoon, M. Hara, M. Hattori, K. Imamura, Chemically modified polysulfone 
hollow fibers with vinylpyrrolidone having improved blood compatibility, Biomaterials. 23 (2002) 2659-2666. doi:10.1016/S0142-9612(01)00406-9.

[33] M.D. Guiver, P. Black, C.M. Tam, Y. Deslandes, Functionalized polysulfone membranes by heterogeneous lithiation, J. Appl. Polym. Sci. 48 (1993) 1597-1606. doi:10.1002/app.1993.070480912.

[34] M.D. Guiver, G.P. Robertson, Chemical Modification of Polysulfones: A Facile Method of Preparing Azide Derivatives from Lithiated Polysulfone Intermediates, Macromolecules. 28 (1995) 294-301. doi:10.1021/ma00105a041.

[35] C. Hoffmann, H. Silau, M. Pinelo, J.M. Woodley, A.E. Daugaard, Surface modification of polysulfone membranes applied for a membrane reactor with immobilized alcohol dehydrogenase, Mater. Today Commun. 14 (2018) 160-168. doi:10.1016/j.mtcomm.2017.12.019.

[36] R. Wang, L. Shi, C.Y. Tang, S. Chou, C. Qiu, A.G. Fane, Characterization of novel forward osmosis hollow fiber membranes, J. Memb. Sci. 355 (2010) 158-167. doi:10.1016/j.memsci.2010.03.017.

[37] K. Jankova, M. Bednarek, S. Hvilsted, Star polymers by ATRP of styrene and acrylates employing multifunctional initiators, J. Polym. Sci. Part A Polym. Chem. 43 (2005) 3748-3759. doi:10.1002/ pola.20834.

[38] T. Xiang, W.-W. Yue, R. Wang, S. Liang, S.-D. Sun, C.-S. Zhao, Surface hydrophilic modification of polyethersulfone membranes by surface-initiated ATRP with enhanced blood compatibility, Colloids Surfaces B Biointerfaces. 110 (2013) 15-21. doi:10.1016/j.colsurfb.2013.04.034.

[39] J. Ran, L. Wu, Z. Zhang, T. Xu, Atom transfer radical polymerization (ATRP): A versatile and forceful tool for functional membranes, Prog. Polym. Sci. 39 (2014) 124-144. doi:10.1016/j.progpolymsci.2013.09.001.

[40] Y. Zhu, F. Zhang, D. Wang, X.F. Pei, W. Zhang, J. Jin, A novel zwitterionic polyelectrolyte grafted PVDF membrane for thoroughly separating oil from water with ultrahigh efficiency, J. Mater. Chem. A. 1 (2013) 5758. doi:10.1039/c3ta01598j. 
- Surface initiated polymerization selectively grafted hollow-fiber PES membranes

- Water flux and solute rejection of membranes controlled by surface modification

- Intentional pore collapse exploited to obtain higher solute rejection

- Extent of pore collapse correlates with the surface grafted polymer 


\section{Conflict of Interest and Authorship Conformation Form}

Please check the following as appropriate:

x All authors have participated in (a) conception and design, or analysis and interpretation of the data; (b) drafting the article or revising it critically for important intellectual content; and (c) approval of the final version.

$\mathrm{x}$ This manuscript has not been submitted to, nor is under review at, another journal or other publishing venue.

$\mathrm{x}$ The authors have no affiliation with any organization with a direct or indirect financial interest in the subject matter discussed in the manuscript

- The following authors have affiliations with organizations with direct or indirect financial interest in the subject matter discussed in the manuscript: 